\title{
MIGRACIONES, ESPACIOS URBANOS Y HOSPITALIDAD
}

\author{
Juan de la Haba* \\ Enrique Santamaría**
}

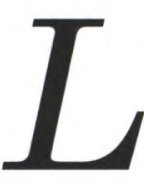

as migraciones internacionales que tienen hoy por destino la geografía hispana nos han llevado a replantearnos, entre otras cosas, las relaciones que los seres humanos mantenemos con y en las ciudades contemporáneas. En éstas, la heterogeneidad sociocultural no sólo se ha convertido en un tema de interés y debate público, sino que constituye un principio organizativo básico. Con ello no queremos decir que aquella sea una novedad propia de las actuales metrópolis, pues, somos conscientes de que es consustancial a la morfología de la ciudad, sino que aquí queremos ceñirnos específicamente a esos entornos urbanos que hoy tienden a calificarse de "multiculturales", principalmente a partir de la presencia y circulación de una amplia gama de migrantes extranjeros que son distinguidos - por ambigua y problemática que sea esta distinción - de la denominada población autóctona.

En estas páginas, queremos ocuparnos de esa antigua institución que es la hospitalidad en relación con las migraciones y los espacios urbanos; una institución que, a lo largo de la historia ha trabajado de manera diversa, aunque muy frecuentemente reducida a la condición de mera virtud, "el interior de la sociedad como una fuerza corrosiva" (Schérer, 1993). Con este fin, partire- mos inicialmente de las formas más persistentes y equívocas de representar las cuestiones urbanas en relación con los procesos migratorios, esbozaremos después una crítica de lo que hemos dado en llamar razón espacial, para, finalmente, apuntar algunas consideraciones sobre cómo pensar hoy en día la hospitalidad en relación con la recepción y el encuentro entre sujetos, sean estos o no "inmigrantes".

\section{PERSISTENTES LUGARES COMUNES}

Con el fin de destacar algunas de las formas más comunes de pensar las dinámicas socioespaciales en las que están insertos "inmigrantes" y "autóctonos", y las trabas teóricas que éstas plantean, tenemos que aludir, lo primero de todo, a esa representación predominantemente "miserabilista" y culturalista del "inmigrante", por la que se asimila automática y acriticamente su llegada e instalación con toda una serie de problemas sociales y de desórdenes urbanísticos. Esta asociación, es obligado decirlo, se presenta anclada no sólo en el imaginario colectivo o en las representaciones mediáticas, sino también en numerosas teorías e investigaciones sociales, y, a este respecto, es del todo necesario no sólo desenmascararla científicamente, sino, muy en particular, inquirir por aquello que en nuestra cultura nos predispone a pensar de esta forma con tanta obstinación.

En las situaciones migratorias la distribución residencial tiende a adquirir una enorme importancia, convirtiéndose en un elemento clave a través del cual se aprehenden y, eventualmente, se solapan o reifican las relaciones sociales. En este sentido, nos parece de gran importancia poner en cuestión tanto la supuesta eficacia socializadora de las formas y de los dispositivos espaciales en sí mismos - o de su poder preventivo ante los riesgos sociales - , como también la concepción inversa del espacio como fuente de situaciones de violencia o de desintegración social. Consecuentemente, queremos referirnos a tres manifestaciones comunes de lo que denominamos razón espacial; esto es, de esa razón en la que lo espacial disuelve lo social, generando unos efectos de cuasinaturalización y opacidad de las dinámicas propiamente sociales.

Por lo que hace a la primera de sus expresiones, la idea fuerza de la "concentración" que suele conducir al omnipresente mitema del "gueto", nos encontramos con una primera lectura de la relación entre espacio y heterogeneidad social en la que cualquier forma de agrupamiento espacial de los 
migrantes hace reaparecer esas figuras estigmatizadas de los "submundos urbanos", tan instaladas en el imaginario contemporáneo, como son las del "enclave" y el "gueto". Sin duda, en esta asimilación de la agrupación y concentración de los migrantes a la imagen del "gueto" subyace también una concepción culturalista de los grupos considerados "impermeables" a la intercomunicación y cerrados social y culturalmente en sí mismos.

Como señalaron Jean-Claude Chamboredon y Madeleine Lemaire en su clásico estudio sobre las grandes áreas de vivienda social de la región parisina (Chamboredon y Lemaire, 1970), la mezcla residencial o la presencia en un mismo espacio de vida de poblaciones diversas no prejuzga a priori las modalidades efectivas de coexistencia que se originarán, las relaciones que se instaurarán entre ellas o las prácticas y representaciones que serán dominantes. Con respecto a este punto, no se insistirá nunca suficientemente en la falsa y equívoca "objetividad" de nociones como las de concentración o dispersión residencial, ni en el peligroso abuso de la noción derivada y tan deformada del "gueto" (ya seaurbano, escolar, laboral, etc.).

Un segundo obstáculo para la comprensión de las implicaciones espaciales de la heterogeneidad sociocultural radica en lo que consideramos una concepción idealizada de la hibridación cultural. Queremos hacer referencia con esto al hecho de que, especialmente, los profesionales de la gestión social y territorial, como también los mismos investigadores sociales, partimos a menudo de lo que llamaríamos el prejuicio de la "compulsión de la mezcla", prejuicio que está en estrecha relación con esa celebración, cuando no sería mejor decir fetichización, de la "diversidad cultural", del "multiculturalismo", que hace de la "mezcla" una solución. Es decir, desde esta representación de la "fusión" cultural se da por descontada la bondad y la eficacia de la mezcla en sí misma, sobreestimándose los efectos positivos que conlleva y omitiendo las condiciones y límites que presenta. De modo que, como con harta frecuencia suele ocurrir, al acercarnos a una realidad concreta solemos sentirnos defraudados cuando lo que se constata más bien son las reservas y la rareza de los contactos, la poca densidad de las relaciones vecinales, su carácter inconsistente, formal o instrumental. Esta supuesta ausencia de relaciones humanas sostenidas, que reduciría éstas a interacciones superficiales, parece no prometer ningún proceso efectivo de "convivencia intercomunitaria", y sí, en cambio, el anuncio de una fuerte diferenciación de los territorios y de las prácticas urbanas, que acabará cristalizando, en algún momento, en la emergencia de una ciudad multicultural segmentada y dislocada.

Esta idealización social del mestizaje, que no deja de ser la réplica en positivo del tabú del "contagio", parte del presupuesto, sumamente engañoso, de que sin aquél no es verosímil, a la larga, la coexistencia sobre un mismo territorio de una diversidad de poblaciones culturalmente diferenciadas, como si en estas circunstancias no fuese posible ir consolidando vínculos sociales, todo y que estos sean débiles y efímeros; $o$, a la inversa, como si con el mestizaje fuera factible superar la disgregación o fragmentación del campo social.

A este respecto, cabe decir que esta retórica del hibridismo cultural, con su convención de la mezcla, no sólo nos dispensa de abordar las cuestiones más decisivas, sino que, además, impide con mucha frecuencia ver un conjunto sutil de pequeñas prácticas culturales que llamamos de reconocimiento, esto es, prácticas de hospitalidad, solidaridad o ayuda mutua, que pueden estar presentes pese a las reservas, indiferencias y distancias recíprocas. En este punto, es menester agregar que no toda superficialidad es degradante. La constatación de la trivialidad de las interacciones en las distintas esferas de sociabilidad urbana no debe evaluarse forzosamente, aunque de hecho así suele hacerse, como un hecho negativo o como mero síntoma de una situación problemática. Tengamos en cuenta que detrás de la indiferencia, no negaremos que real, hay también muchas veces, como nos advierte Pierre Mayol (1990), un incansable trabajo de curiosidad.

Por último, queremos llamar la atención sobre esa otra manifestación de la razón espacial en la que, a través del predominio entre proyectistas, operadores y promotores inmobiliarios (ya sean estos públicos o privados) de consideraciones y dispositivos técnicos, incluso estéticos, la planificación urbana deja de ser concebida como un proceso social. Junto a este oscurecimiento tecnocrático y estetizante de las relaciones sociales y/o del conflicto social en el espacio, se sostiene, una confianza injustificada y obstinada en la función del diseño urbano o en las virtualidades de un medio arquitectónico estético o artístico al objeto de edificar mundos urbanos con relaciones innovadoras, de construir lugares públicos significativos, de "infundir vida" a un espacio habitado o de crear una cultura cosmopolita común. Así, de su campo de acción suele desaparecer toda consideración a los moradores como sujetos locales, coproductores del espacio y sus lugares, haciendo de ellos meros consumidores espaciales. Se excluye, pues, en el proceso de construcción de lugares, la parte que le corresponde a la deliberación, sea ésta más o menos conflictual; o, lo que viene a ser lo mismo, se ignora que ese proceso está sometido a factores sociales y elementos de contexto que no pueden ser dominados de forma completa por los arquitectos o urbanistas, como es, entre otros, la actividad social y la práctica cultural de los sujetos locales que los ocupan y que, en definitiva, son las que los dota de un valor y un significado pú- 
blico.

En definitiva, y tras todo lo dicho, podemos considerar que la inscripción en el espacio físico de las relaciones sociales, su expresión en forma de $l u$ gares, posibilita que queden oscurecidas las dimensiones propiamente sociales a favor de explicaciones espontaneamente sustancialistas y reduccionistas. En otras palabras, el espacio construido y heredado puede tener la virtualidad de retraducir el espacio social, pero siempre de una manera más o menos turbia o confusa, produciendo un efecto de naturalización de las realidades sociales o, por decirlo con un giro de Pierre Bourdieu (1993), generando unos "efectos de lugar".

\section{¿SE PUEDE HABLAR DE ESPACIOS HOSPITALARIOS O INHÓSPITOS?}

Para esta pregunta Georg Simmel ya nos adelantó una respuesta. En efecto, Simmel, además de sostener la idea de que "el espacio es una forma que en sí misma no produce efecto alguno", nos advertía de que, por evidente que pueda parecer, no son las formas de la proximidad o de las distancias espaciales las que producen los fenómenos de la vecindad y la extranjería, de la hospitalidad o la hostilidad (1986: 644). Por consiguiente, no sería posible hablar de espacios segregadores ni de lugares hospitalarios o inhóspitos, sino, que de lo que verdaderamente habría que hablar es de usos segregadores o usos y ocupaciones hospitalarios del espacio. Pero detengámonos un poco más en la cuestión.

La primera experiencia compartida que tienen los diversos grupos que residen en un mismo territorio es precisamente su inscripción territorial; o sea, su ubicación en el orden de las coexistencias posibles que se realizan en los lugares. Esto puede parecer obvio, pero sin duda contiene innumerables consecuencias. En la medida en que, con su contigüidad física, los individuos participan de un lugar común, la regulación de sus relaciones e interacciones, no siempre intencionales pero sí obligadas, pasa por una adecuación de los diversos usos del espacio o, más específicamente, de la situación de vecindad y del barrio como unidad de cohabitación. En el caso de los procesos migratorios, esto se expresa precisamente, al menos en las primeras fases, en un incremento de la importancia de los dispositivos espaciales en las relaciones sociales y en la formación del orden social local, lo que, eventualmente, puede llevar a una mayor proyección de los desacuerdos o puntos de fricción sobre alguna región del espacio urbano; esto es, a que el conflicto social se vea traducido, turbia o soterradamente, en conflicto espacial.

Planteado de esta manera, el discernimiento de las diversas lógicas de espacialización de la diversidad y de la distancia sociocultural aparece como una tarea compleja. A este propósito habría que contemplar un conjunto variado de aspectos sociourbanísticos, pero, en este punto, el tratamiento de los espacios públicos nos parece de relevancia suficiente como para requerir una atención más específica en tanto que nódulo fundamental en la intersección entre espacio y heterogeneidad social. En el espacio público, como lugar principal de la gestualidad social, se explora y ensaya la sociabilidad y la identificación, con todas sus posibles derivaciones culturales, políticas, etc. Pero, por otro lado, es un espacio socialmente determinado y, por ende, asimétrico y jerarquizado en su conocimiento, accesibilidad, movilidad o apropiación. El uso y control del espacio es, así, un atributo social minuciosamente estratificado. Los individuos y los grupos no disponen de un acceso igual a la presencia o a la localización, y, en consecuencia, en sus usos y representaciones dejan patentes sus capacidades diferenciales de apropiación y de codificación del espacio urbano.

En los entornos urbanos, la constitución de (auto)dominios específicos (incluso marcados "étnicamente") es un modo inmediato de acomodación del que disponen los grupos que cohabitan en situación de heterogeneidad sociocultural. En estos contextos, la afirmación identitaria sobre el espacio público, sobre sus objetos y referentes físicos, no debe ser interpretada de forma unívoca como una negación de la coexistencia, sino más bien como un reflejo de las distancias sociales o culturales, y sobre todo como un modo - variable, inacabado y sujeto a permanentes reformulaciones o compromisos - de gestión de los alejamientos y reconocimientos socioculturales. En ella se contiene ante todo una pugna por regular y controlar la visibilidad, la ocultación o el anonimato propio y, eventualmente, la existencia/inexistencia de los otros.

A modo de ilustración de lo que estamos diciendo, podemos referirnos al hecho de que la mayor parte de los conflictos que en el territorio español han sido calificados como "interétnicos" y cuya interpretación, en lo fundamental, ha sido reducida a la condición de "brotes de racismo y xenofobia", han tenido en común, precisamente, su focalización sobre el espacio, o lo que es lo mismo, han "estallado" inicialmente a partir de una disputa por la definición y apropiación de determinados lugares urbanos. Digamos que, principal, pero no de manera exclusiva, de plazas o parques. En estos casos, puede verse, aunque no podamos redundar demasiado en ello, cómo el territorio llega a adquirir una enorme fuerza simbólica; cómo deviene un signo con el que operan unos y otros sectores - nunca reducibles, es fundamental no olvidarlo, a la polaridad "inmigrantes"/ "autóctonos"- - de cara a realizar, sobre el espacio urbano objetivado, sus intereses, apuestas o posiciones sociales. Estos acontecimientos muestran, 
además, el hecho de que la proyección espacial que se hizo de cada conflicto oscureció la percepción de otros componentes sociales determinantes de los antagonismos y enfrentamientos, de modo que, de una u otra forma, lo espacial vino a diluir y reificar lo social, al mismo tiempo que esa opacidad le devolvía al espacio la apariencia de realidad sustancial.

De este modo, lo acontecido, por ejemplo, en los barrios de Aravaca y de Ca n'Anglada, dos barrios que han pasado a ser emblemáticos de la geografía del racismo en España, aunque sea de naturaleza diferente, nos puede servir para comprender algunas de estas cuestiones. Así, una de las conclusiones que se extrae del análisis de Gladys Nieto y Adela Franzé (1997) en torno a las hostilidades vecinales generadas por las «concentraciones» de mujeres dominicanas en la Plaza de la Corona Boreal, en Aravaca, es que lo que se trataba de presentar, de reducir y de estigmatizar como una "cuestión inmigrante" asociándose la presencia de las dominicanas con la suciedad, el tráfico de drogas, la prostitución, la exhibición sexual o el ruido, era un antagonismo que tenía ciertamente un alcance mucho mayor y en el que se solapaban muy diversas cuestiones, relacionadas con el hecho de que Aravaca ha ido ocupando una posición de prestigio en la estructura social urbana de Madrid, al haberse transformado en una zona de atracción para las clases medias altas y de construcción de lujosos edificios de apartamentos a principios de los 90 para reemplazar los viejos edificios del centro histórico. A este respecto, no deja de ser muy iluminador el hecho de que una de las demandas que el vecindario formulaba durante el conflicto en torno a "la plaza", a su "invasión" por parte de las inmigrantes, fuese su separación de Madrid, para agregarse al colindante municipio de Pozuelo, una de las zonas más reputadas del área metropolitana madrileña.

Por su parte, los problemas vecinales de Ca n'Anglada, un barrio popular de la ciudad catalana de Terrassa, darían testimonio de cómo su reinterpretación en términos de aliedad, de radical alteridad, en la que el inmigrante extranjero es percibido y representado con rasgos amenazantes - en lo sustancial a través de su notoria presencia física y su alta movilidad por los espacios de interacción, como, en este caso, la popularmente llamada "Plaza Roja" - conduce a encubrir aspectos más fundamentales y anteriores en el tiempo, como el deterioro de las solidaridades de clase producido por la fragilización de las relaciones de trabajo, después de importantes transformaciones del empleo en la industria metalúrgica de la zona, y el debilitamiento de las tramas relacionales y la pérdida de capacidad de control sobre un espacio habitable; aspectos estos que habían caracterizado la cultura obrera de un barrio nacido al albur de la inmigración de los años 60 y 70, procedente en este caso de las otras zonas de España.

Hagamos un breve inciso en este punto para señalar que estas formas de escenificación de la "diferencia cultural" llevan además a oscurecer la acción de un principio de división que nos parece más fundamental y que es aplicado de forma indistinta y más versátil, según los contextos, a muy diversas categorías sociales, y no sólo a las que tienen otros orígenes "nacionales" u otras referencias "étnicas" que implicasen, supuestamente, una "alteridad cultural": nos referimos a la oposición, ya sugerida por Norbert Elias (1965), entre los "antiguos" y los "nuevos" vecinos "los de toda la vida" y los "recién instalados"-; esto es, al tiempo como dimensión fundamental de división y cualificación social.

La localización, la movilidad, el desplazamiento se convierten, pues, en ámbitos principales de proyección de ciertos conflictos y hostilidades sociales, y también de ocultamiento de otras apuestas y otros principios de división. En todo caso, el estudio de las interacciones urbanas en condiciones de multiplicidad y efervescencia sociocultural debe evitar que el origen "étnico-cultural" devenga una verdadera categoría social e intelectual en sí. Que se convierta en un principio explicativo en lugar de aquello que debe ser explicado, favoreciendo así una percepción y una categorización dicotómica ("autóctonos"/"inmigrantes") que, en el mejor de los casos, lleva sólo a focalizar la mirada sobre los problemas de cohabitación entre "comunidades", a interpretar la agregación y la cualificación "nacional" o "étnica" del espacio como manifestación de una lógica diferencialista. Lo que, como hemos señalado, impide captar la diversidad y complejidad de las situaciones urbanas así como comprender los envites, las contradicciones y las luchas heterogéneas pero propiamente sociales que se desarrollan tanto en el interior del campo "inmigrante" como en el "autóctono".

A todo esto hay que añadir que, para acabar de completar estas disquisiciones nos falta tomar en consideración lo relativo a la coexistencia y connivencia. Efectivamente, hasta ahora nos hemos venido centrando en el hecho de que coincidir, compartir y a la vez pugnar por un mismo lugar de vida lleva a cada grupo a desarrollar prácticas relacionales de distinción y distanciamiento; ahora bien, no pueden ignorarse otras prácticas complementarias de reconocimiento, de conciliación, de negociación, a veces extremadamente sofisticadas, sutiles, de cara simplemente a hacer posible y aceptable para todos la vida en común, y ello a pesar de la heterogeneidad de las trayectorias sociales y los referentes culturales de unos u otros. $\mathrm{Al}$ respecto, en los espacios de vida se impone un savoir faire de la coexistencia indeterminado e inevitable a la vez. Con 
el fin de comprender mejor estas prácticas, sería oportuno retomar la noción de táctica, elaborada por Michel de Certeau (1990), y englobar en ella todo un conjunto diverso de prácticas culturales de hospitalidad, de intercambio y de reconocimiento - las cuales no evitan la acción paralela e incluso entre los mismos actores, de otras formas de competencia, de distanciamiento o desconocimiento - entre aquellos que cohabitan e interaccionan en un mismo espacio social. Se podría afirmar a este respecto, y por usar términos del mismo autor pensados para otros propósitos, que hay una creatividad oculta, dispersa, táctica y transitoria de las gentes ordinarias y en los espacios más corrientes en cuanto a las prácticas de hospitalidad y reconocimiento, unas astucias cotidianas, triviales, silenciosas, a veces furtivas, pero eficaces, al lado de las técnicas de dominio sobre las diversas regiones del espacio, que es necesario desvelar.

Como ya hemos evocado anteriormente, tal vez se trata de comprender que las relaciones vecinales y ciudadanas no siguen tanto una lógica de "profundización" como de aproximaciones sucesivas y discontinuas $\mathrm{y}$, sobre todo, de intercambios materiales y simbólicos, banales pero imprescindibles para la "economía social" del lugar de vida, o para, digámoslo así, la "economía del reconocimiento", que establecen de una forma variable, cambiante, los distintos grupos que concurren en un mismo espacio. Con ello lo que estamos proponiendo es que la temática de la heterogeneidad urbana sea reformulada en términos de una problemática de las transacciones sociales, que diría Jean Remy (1998), y de las transacciones en su interacción con los atributos del espacio urbano; problemática donde situaríamos los temas propios de la coexistencia como son la hospitalidad, la distancia, la reserva o la hostilidad, entendidas éstas como categorías sociológicas.

\section{LA HOSPITALIDAD: UNA CATEGORÍA SOCIOLÓGICA}

Llegados a este punto, nos parece del todo oportuno introducir, aunque sea de manera incidental, algunas consideraciones en torno a la noción de hospitalidad, para poner de relieve que los diversos significados de los términos "hospitalidad" y "hospitalario" parecen relacionar el espacio y la protección, o lo que es lo mismo, la idea de proveer un lugar de recepción (de alojamiento, cobijo, acogida) y la de procurar una tutela (o sea, amparo, seguridad, generosidad). De una manera o de otra, históricamente la hospitalidad se ha asociado con la necesidad de disponer un espacio protector para el otro. Por esta razón, consideramos de sumo interés explorar la hospitalidad como una categoría sociológica, así como la estructura social de la hospitalidad, para restituirle un carácter de hecho público. Esto requiere poner en obra una aproximación socioantropológica a las prácticas relacionales y transaccionales de hospitalidad y de solidaridad - en general de lo que llamamos las diversas figuras culturales del reconocimiento social -; una aproximación que las considere como un atributo de las estructuras sociales y no meramente como acciones espontáneas, arbitrarias o simplemente ejemplares de las consciencias individuales. Indiquemos, además, que, desde esta perspectiva, la hospitalidad y las otras figuras del reconocimiento tampoco se limitan de forma exclusiva a la dimensión sociojurídica, con su entramado de derechos y deberes relativos tanto al hospedante como al huésped. De manera que, a nuestro modo de ver, pertenecen a esas prácticas culturales, por comunes o triviales que sean, en las que se puede encontrar una articulación entre el juego de las estructuras y el juego de las acciones sociales. Cabe, pues, conside- rar que la hospitalidad es, socioantropológicamente hablando, un acto cultural, una creación sociohistórica, y, por ende, la cuestión a interrogar no es la de ser o no hospitalarios, sino cuáles son los gestos, los códigos e instituciones que expresan y vehiculan la hospitalidad en cada tiempo y lugar.

En este sentido, y para no extendernos más de lo debido, concluiremos con dos pequeños corolarios. En primer lugar, y con relación al espacio objetivado, nos parece importante reafirmar la proposición que se enunció al principio: no cabe hablar de espacios hospitalarios o inhóspitos en sí, sino que partiendo siempre de la idea de proceso social, habrá que pensar en términos de usos y ocupaciones hospitalarias o inhóspitas del espacio urbano. Y las condiciones de posibilidad de los usos hospitalarios y protectores radican prioritariamente en la capacidad política de control que sobre su hábitat, sus lugares y sus viviendas, sobre los procesos constructivos y urbanos, tienen los habitantes y los usuarios capacidad limitada o anulada por los obstáculos de la propiedad, la financiación, la legislación y la autorización, etc.-, que no con el diseño territorial, artístico o arquitectónico de los mismos. De este modo, en materia de arte de habitar tenemos que referirnos más a las exigencias políticas que a los criterios técnicos o estéticos que recubren la lógica de la producción y el consumo del espacio.

Por otro lado, y situándonos en un registro más general, pensamos que la hospitalidad no resuelve la cuestión de la distancia. A este respecto, conviene no ignorar la ambigüedad sociopolítica constitutiva de la figura del "huésped": la permanencia en la condición de huésped implica que su extrañeza continúa en vigor de modo indefinido, a veces, imperativo, que certificamos la insularidad de su diferencia o que lo 
recluimos en lo que G. Simmel (1986) llamaba la interinidad del llegar y el marchar. No obstante, y como contrapunto, las leyes de la hospitalidad nos impelen a acoger y proteger al huésped sin despojarle de su extrañeza o exculparle de esa peculiaridad. Desde luego, la categoría de hospitalidad no puede tomarse como fórmula de inteligibilidad ni como alternativa a los dilemas planteados por la dialéctica de las desigualdades, de lo plural y lo singular o de lo propio y lo extraño. Conscientes de sus ambigüedades y asimetrías, sin embargo, no por ello es despreciable hoy, frente, por ejemplo, a las atrocidades y sinsentidos de las leyes de extranjería que en tantos países suponen un menosprecio de la razón y la dignidad de los seres humanos. Pero, más aún, lo que nos interesa subrayar ahora es el valor de las formas de la relación con la especificidad de los otros o con la extrañeza - y a veces con la contrariedad — de la vida, como revelador crítico del carácter real de una sociedad. A este propósito, el tema de la hospitalidad implica una reflexión básica sobre el vínculo social y sobre el trato que en una época o en una sociedad se dispensa a las personas. Si el vínculo social, en cualquier sociedad, se sustenta en el reconocimiento de la limitación y la necesidad mutua - aunque desigual -, entonces pensamos que son muy oportunos los análisis de Richard Sennet (1991) que muestran cómo las verdades más inconcusas e inflexibles del actual orden social "flexible" tratan la dependencia y la indefensión como condiciones vergonzosas y vergonzantes. El capitalismo, en tanto que economía política, socava las formas de hospitalidad, en la medida en que denigra toda figura de la dependencia y la complementariedad entre individuos ante la necesidad mutua. Así pues, el principio de la hospitalidad se contrapone hoy a las diatribas sobre el "parasitismo social" que laten en el cuestionamiento de los derechos y los sistemas de protección social, o dicho de otro modo, en la producción de lo que Robert Castel (2004) ha dado en llamar certeramente "inseguridad social".

En resumidas cuentas, lo que estamos tratando de proponer no es una aproximación a la hospitalidad en tanto que gesto o forma de contacto entre extraños, pues eso no sería más que un remedio pobre para situaciones sociales complejas, sino la relación de hospitalidad considerada como un vínculo que emerge en el juego de inclusiones y distancias, de dependencias y sagaces silencios, de obligaciones y asimetrías, de autonomías y mutualidades, y que vale como modelo para una estructura social que requiere estar capacitada objetivamente para establecer una sólida relación social en la que la consideración seria de las necesidades de los extraños sea posible junto a la voluntad o el interés por seguir permaneciendo extraños.

Acabemos, pues, este pequeño artículo planteando, con palabras de nuevo tomadas de René Schérer, y a modo de programa de investigación, toda una serie de interrogantes sobre esta institución social intersticial que es la hospitalidad: “¿Quién en nuestros días ofrece hospitalidad? ¿Quién está en condiciones de ofrecerla y a quién? ¿Qué lugar ocupa en la vida contemporánea: el centro o los confines? ¿Es la primera de las inquietudes cotidianas, organizadora de un modo de vida, o es un lujo episódico que algunos pueden ofrecerse y ofrecer? ¿Un accidente de la existencia, cuando no es gravosa, o algo que descargamos en instituciones especializadas?".

* Juan de la Haba es profesor de la Facultad de CC PP y Sociología en el Centro Asociado de la UNED de Terrassa. Miembro del Grupo de Investigación en Antropología y Sociología de los Procesos Identitarios (ERAPI), del Instituto Catalán de Antropología.

** Enrique Santamaría es profesor en el Dep. de Sociología de la
Universidad Autónoma de Barcelona (UAB) y miembro del Grupo de Estudios sobre Inmigración y Minorías Étnicas (GEDIME), de dicho departamento. Miembro del Grupo de Investigación en Antropología y Sociología de los Procesos Identitarios (ERAPI), del Instituto Catalán de Antropología.

\section{REFERENCIAS BIBLIOGRÁFICAS}

BOURDIEU, Pierre

(1993): "Effectes de lieu», en P. Bourdieu (dir.), La Misére du Monde, Paris: Seuil.

CASTEL, Robert

(2004): La inseguridad social. ¿Qué es estar protegido?, Buenos Aires: Manantial.

CHAMBOREDON, Jean Claude et LEMAIRE, Madeleine

(1970): «Proximité spatiale et distance sociale. Les grands ensembles et leur peuplement», Revue française de sociologie, vol. 11, Paris.

DE CERTEAU, Michel

(1990): L'invention du quotidien 1. Arts de faire, Paris: Gallimard.

ELIAS, Norbert

(1965): The Established and the Outsiders, London: Sage Publications.

MAYOL, Pierre

(1990): «Habiter», en Luce Girad et Pierre Mayol, L'invention du quotidien 2. Habiter, cuisiner, Paris: Gallimard, pp. 11-146.

NIETO, Gladys and FRANZÉ, Adela (1997): «Social Conflict and Urban Space. The Plaza de la Corona Boreal», Current Anthropology, vol. 38, no 8 .

REMY, Jean

(1998): "La transaction sociale, forme de sociabilité et posture méthodologique", en M.-S. Freynet, M. Blanc et G. Pineau (dir.), Les transactions aux frontiéres du social, Lyon: Chronique Sociale.

SCHÉRER, René

(1993): Zeus hospitalier. Éloge de l'hospitalité, Paris: Armand Colin.

SENNETT, Richard

(1991): La consciencia del ojo, Barcelona: Versal.

SIMMEL, Georg

(1986): Sociologia. Estudios sobre la forma de socialización, vol. II, Madrid: Alianza. 